\title{
Control strategy of segregation on HVAC energy efficiency as non propulsion electrical hotel load in EV
}

\begin{abstract}
A maximum cruising range is adversely affected by electric power consumption of auxiliary electric components for heating and cooling. Under the assumption that range anxiety is one of the main barriers to the electrification of an Electric Vehicle (EV). Considering a heating ventilation air-conditioner (HVAC) system as a non propulsion electrical hotel load consumed more energy that respect to time and thermodynamic circumstances. This paper presents a control strategy on segregation of non propulsion electrical hotel load energy efficiency for an EV. A good HVAC control system, enhance the thermal comfort that will lead to better energy efficiency and driving performance. A concept of enthalpy in analyzing the heat exchange involved to decomposed into sensible heat and latent heat for dynamics of temperature and humidity ratios of the car compartment derivation after taking into account of the differences of ASHF (Apparatus Sensible Heat Factor) and RSHF (Room Sensible Heat Factor). The goal of a PD-type Fuzzy Logic Control (PD-FLC) based controller is to satisfy the convergence and equilibrium properties. The proposed strategy is composed of three part: temperature error, temperature change of error, and the relative humidity error to control the heater damper voltage, outside air damper voltage and blower fan voltage. The control strategy is evaluated in a Matlab/Simulink simulation environment, which performs a better energy efficiency.
\end{abstract}

Keyword: Energy efficiency; Non propulsion electrical hotel load; HVAC; EV; PD-FLC; GA; Control strategy 